\title{
Desigualdad social, sociedad civil y los límites de la ciudadanía en América Latina
}

\author{
PHILIP OXHORN*
}

\begin{abstract}
The goal of this paper is to apply certain insights from Marshall dealing with the interrelationship between distinct types of citizenship rights and social inequality in order to understand some of the principal challenges facing Latin American democracies today. I propose to understand the development of citizenship rights as a process intimately linked to the development of civil society. In the first part of the paper, I argue that citizenship rights are socially constructed, and the second section approaches to the case of the social construction of citizenship rights in Latin America.
\end{abstract}

Keywords: citizenship rights, civil society, social inequality.

\section{Resumen}

El objetivo del artículo es aplicar algunas de las ideas de Marshall acerca de la interrelación entre diversos tipos de derechos ciudadanos y la desigualdad social para entender algunos de los principales retos enfrentados por las democracias de América Latina. Se propone entender el desarrollo de los derechos ciudadanos como un proceso íntimamente vinculado con el desarrollo de la sociedad civil. En la primera parte se argumenta que los derechos de ciudadanía son socialmente construidos, mientras que en la segunda parte se presenta el caso de la construcción de los derechos ciudadanos en América Latina.

Palabras clave: derechos ciudadanos, sociedad civil, desigualdad social. 


\section{Introducción ${ }^{1}$}

Al menos desde Aristóteles, la existencia de la desigualdad social ha representado un problema central para la teoría y la práctica democráticas. No obstante, las sociedades más igualitarias han sido a menudo las menos democráticas. En realidad, aquellas formas de gobierno que han logrado los más altos niveles de equidad social lo han hecho sin lugar a dudas a expensas de la participación democrática y de los derechos ciudadanos. En la antigüedad, la igualdad social en la polis se conseguía limitando la ciudadanía a un pequeño grupo de hombres que detentaban la propiedad, cosa que sería intolerable hoy en día. Más recientemente, en el antiguo bloque soviético, China, Cuba y otros regímenes, la equidad social se alcanzaba eliminando cualquier concepto significativo de ciudadanía democrática y reprimiendo a la sociedad civil, lugar natural para el ejercicio de tales derechos. Irónicamente, los crecientes niveles de desigualdad social asociados con la introducción de reformas económicas basadas en el mercado contribuyeron a la transición democrática en Europa del Este y en la desaparecida Unión Soviética al socavar el implícito contrato social comunista, y hoy en día, reformas similares a estas podrían contarse entre las más serias amenazas a la legitimidad de los regímenes chino y cubano. Aún en las economías de mercado, fuera de la estrecha experiencia histórica de las democracias políticas occidentales y del Japón (y en muchos casos sólo después de la Segunda Guerra Mundial), los relativamente altos niveles de equidad social en los países en vías de desarrollo a menudo han ido de la mano con gobiernos autoritarios. Mientras que la presencia de regímenes autoritarios de ninguna manera garantizaba el desarrollo equitativo, ${ }^{2}$ en estos términos los regímenes más exitosos tendían a ser regímenes cerrados y represivos, como por ejemplo los casos de Taiwán o Corea del Sur.

Aun esta superficial discusión sugiere una paradoja importante: aunque la democracia puede, en última instancia, ser socavada por la desigualdad socioeconómica, un cierto nivel de desigualdad parece ser casi inevitable dada la realidad de las políticas democráticas. ${ }^{3}$ La razón de ello es que la desigualdad es inevita-

${ }^{1}$ Traducción de Alma Mancilla. El artículo original en inglés fue publicado en la página de Internet de Latin American Studies Association, <http://lasa.international. pitt.edu/98democratization.htm>

${ }^{2}$ La historia de América Latina ofrece el más claro ejemplo de esto. Y como demuestran los casos de México y Bolivia, lo mismo puede decirse de las revoluciones.

${ }^{3}$ Quizá por esta razón, lo mejor a lo que puede aspirarse es a un decremento gradual de los niveles de desigualdad social (Véase Przeworski et al., 1996). 
ble en las economías de mercado, tal y como fue reconocido por Marx (si bien de manera exagerada) hace tanto tiempo. Los esfuerzos de 'nivelación' social van a enfrentar una dura resistencia, aun si tienen lugar a través de las instituciones democráticas. En la mayor parte de los países de Latinoamérica (y también en muchas otras democracias) puede incluso existir una correlación directa entre el nivel de desigualdad y la resistencia a las medidas tendentes a mejorar los niveles de equidad. En otras palabras, los extremos de la desigualdad socioeconómica pueden incrementar los riesgos de las políticas de redistribución, haciendo que las reformas sustanciales sean menos probables precisamente en aquellos países en que más se requieren para el mantenimiento de la estabilidad democrática. ${ }^{4}$

Aquí subyace la visión principal de T.H. Marshall (1950): la desigualdad social puede ser legitimada en las democracias occidentales sólo a través de la extensión y expansión gradual de los derechos universales de ciudadanía. En lo que demostraría ser un verdadero círculo virtuoso a lo largo de alrededor de 300 años de historia británica, y por extensión, europea (Bendix, 1964), la evolución de los derechos ciudadanos que da inicio con el establecimiento de los derechos civiles y que progresa a través de la estipulación de los primeros derechos políticos, y posteriormente sociales, de ciudadanía legitimó la desigualdad social asociada al capitalismo, al mismo tiempo que proporcionó los fundamentos sociales y políticos sobre los cuales pudo prosperar el capitalismo moderno.

Es precisamente esta visión la que es a menudo pasada por alto en los debates recientes acerca de la ciudadanía, aún cuando ha habido un resurgimiento mundial del capitalismo liberal, especialmente en América Latina. En lugar de ello, los desafíos principales discutidos en la literatura con frecuencia giran alrededor de la 'profundización' o la extensión de los derechos de ciudadanía para incluir en ellos nuevas dimensiones y nuevas identidades que Marshall jamás contempló, como el género, la etnicidad, la ecología y la comunidad, por mencionar sólo algunos (Beiner, 1995; Mouffe, 1992; Turner, 1993; Hobson y Lindholm, 1997; Garretón, 1998). De muchas maneras, estos desafíos ponen a

\footnotetext{
${ }^{4}$ Como ha advertido Usher (1981: 98): “...si, como Marx predijo y sus seguidores han repetido desde entonces, la distribución del ingreso está empeorando constantemente...entonces se vuelve improbable, casi imposible que la democracia continúe, debido a que los trabajadores con el poder político para desplazar a los capitalistas estarían eventualmente inclinados a hacer eso, y los capitalistas o sus sucesores, en ese punto, abolirían la democracia para preservar su posición privilegiada”.
} 
prueba los límites del pluralismo en el interior de los Estados Nación, así como la manera en que estos límites a menudo entran en conflicto directo con lo que con frecuencia ha sido identificado como la principal amenaza a la ciudadanía moderna: la mermada capacidad de los estados para garantizar de manera efectiva los derechos fundamentales de ciudadanía debida a los procesos globales de cambio económico y tecnológico, y al ascenso de los nacionalismos étnicos. Tales amenazas y desafíos parecen quedar por completo fuera de la estrecha visión de Marshall acerca de las clases sociales. Muchos de los llamados nuevos movimientos sociales, en particular los de las mujeres y los grupos indígenas, pueden ir incluso más lejos, al desafiar los presupuestos fundamentales sobre los cuales se han edificado las concepciones liberales de los derechos, incluyendo la de Marshall. ${ }^{5}$

$\mathrm{Al}$ mismo tiempo, el ascenso sin precedentes de la democracia política alrededor del mundo, lo mismo como tipo ideal que como realidad empírica, con las concomitantes garantías democráticas de los derechos políticos básicos, ha alejado la atención del enfoque original de Marshall acerca de la evolución de los derechos ciudadanos. El enfoque se centra ahora sobre todo en tratar de entender la calidad de los regímenes democráticos existentes en el antiguo bloque soviético y en la mayor parte del mundo en vías de desarrollo (Oxhorn y Ducatenzeiler, 1998; Jelin y Herschberg, 1996; NACLA, 1996; Przeworski, 1995; Smith et al., 1994; O'Donnell, 1993 y 1994). Este trabajo subraya la importancia de no ser complaciente con la existencia de derechos políticos identificados con elecciones competitivas y relativamente libres. Si bien estos regímenes democráticos pueden durar mucho tiempo, ello puede deberse más a la inercia y a la falta de alternativas viables que al ejercicio efectivo de los derechos ciudadanos asociados con los regímenes democráticos en Occidente (Oxhorn, 1998a; Przeworski, 1986). Dejando de lado los altos costos sociales implicados por los severos límites en los derechos ciudadanos (crimen, pobreza, inseguridad económica, entre otros), siempre existe el peligro de que los crecientes niveles de frustración social sean expresados, ya sea en un resurgimiento del populismo demagógico, o bien en la reaparición de extremismos, tanto de derecha como de izquierda (Oxhorn, 1998b). En un patrón muy diferente del descrito por Marshall hace casi medio siglo, la garantía de los derechos políticos en muchas democra-

${ }^{5}$ Estoy en deuda con Nancy Thede por recordarme acerca de este punto. 
cias nacientes ha ido acompañada por una naturaleza cada vez más precaria de los derechos civiles, así como por los crecientes límites -cuando no revocaciones- de los derechos sociales de ciudadanía.

En este trabajo intento aplicar algunas de las ideas de Marshall acerca de la interrelación entre diversos tipos de derechos ciudadanos y la desigualdad social, con el propósito de comprender algunos de los principales retos que enfrentan actualmente las democracias en América Latina. Más allá de lo que Marshall afirma, y en respuesta a algunos de sus críticos, propongo entender el desarrollo de los derechos ciudadanos como un proceso íntimamente vinculado con el desarrollo de la sociedad civil. En la primera parte de este documento, sostengo que los derechos ciudadanos son socialmente construidos, y que ahí donde la sociedad civil es débil, la construcción social de los derechos ciudadanos es por consiguiente más precaria. De manera más específica, reinterpreto los argumentos de Marshall acerca de la evolución de los derechos ciudadanos sugiriendo que el proceso que Marshall describió reflejaba la acumulación de recursos de poder por parte de la clase obrera británica.

La fuerza creciente de la clase obrera fue la razón principal por la que se institucionalizaron los derechos civiles, y el fortalecimiento de éstos también ayudó a institucionalizar la preexistente fuerza organizativa de la clase obrera al mismo tiempo que echaba a andar los procesos a través de los cuales continuó su crecimiento. Después contrasto brevemente la experiencia británica con la de los obreros en la Alemania de Bismark, y con la de varios países latinoamericanos en donde no tuvo lugar algún proceso similar de acumulación de poder. Concluyo la sección haciendo referencia a la complicada situación de los derechos ciudadanos de género en Europa del Este, en donde el hecho de que estos derechos fueran garantizados desde arriba durante el periodo comunista ha contribuido a su debilitamiento en el periodo poscomunista debido a la falta de una base social.

La segunda parte del documento da cuenta de algunos problemas particulares en las democracias actuales de América Latina. Mi argumento es que los derechos políticos a menudo han precedido la garantía efectiva de los derechos civiles fundamentales, los cuales continúan siendo marcadamente débiles en muchos países. Sostengo que las luchas populares contra las dictaduras de las décadas de 1970 y 1980 no llevaron hacia el mismo proceso acumulativo descrito por Marshall, esto debido a que la 
naturaleza elitista de estas transiciones a menudo truncó el proceso por medio del cual se desarrolló la sociedad civil. Esto es también un reflejo de los procesos paralelos de cambio económico que han tendido a fragmentar y a desarticular a la sociedad civil. Las nuevas políticas económicas neoliberales han contribuido a la mercantilización del ejercicio del derecho a medida que el papel del Estado en la sociedad es dramáticamente reducido. En las conclusiones, exploro algunas posibles alternativas para contribuir a un mayor desarrollo de la sociedad civil en tanto mecanismo esencial para la expansión de los derechos ciudadanos y para el mejoramiento de la calidad de las democracias latinoamericanas.

\section{La sociedad civil y la construcción social de la ciudadanía}

En su clásico estudio de la evolución histórica de los derechos ciudadanos, T.H. Marshall (1950) argumentaba que la ciudadanía era aquel estatus de igualdad de derechos y obligaciones compartido por todos los miembros de una comunidad política. Como tal, "[el] estatus diferencial, asociado a la clase, la función y la familia, fue reemplazado por el estatus uniforme de la ciudadanía, lo que proporcionó los fundamentos de la desigualdad sobre los que se pudo edificar la estructura de la desigualdad [capitalista]" (Marshall, 1950: 34). El contenido específico de los derechos y deberes de la ciudadanía evolucionaría paso a paso con los requerimientos de la acumulación capitalista. Como consecuencia, afirma Marshall, los derechos políticos en los regímenes que son hoy democráticos liberales iban necesariamente precedidos por garantías de derechos civiles fundamentales para los grupos subalternos (principalmente para la clase obrera). Una vez que los derechos políticos se hicieron extensivos a todos los ciudadanos, la evolución de los derechos de ciudadanía pudo pasar a un nuevo plano caracterizado por la expansión de los derechos sociales de ciudadanía asociados con el moderno Estado benefactor.

Empleando como modelo a Gran Bretaña, Marshall vio el surgimiento de los modernos derechos universales de ciudadanía como esencialmente paralelo al crecimiento de las economías de mercado. El proceso dio inicio en el siglo XVIII, según Marshall, tanto porque la naciente economía capitalista necesitaba la institucionalización de los derechos de la propiedad a través del reforzamiento de los derechos civiles fundamentales, como porque 
la nueva sociedad capitalista tenía que legitimar la resultante desigualdad social con una nueva esencia: la de ciudadanía. Con el fin del feudalismo, "la historia de los derechos civiles en su periodo formativo es de acumulación gradual de nuevos derechos a un estatus que ya existía y que se concebía como perteneciente a todos los miembros adultos de una comunidad... Este carácter democrático, o universal, del estatus surgió naturalmente del hecho de que se trataba en esencia del estatus de libertad, y en la Gran Bretaña del siglo XVII, todos los hombres eran libres" (Marshall, 1950: 18). De esa manera, los derechos civiles se convirtieron en la piedra angular de las modernas concepciones de ciudadanía, incluyendo "...los derechos necesarios para la libertad individual -libertad de la persona, libertad de palabra, pensamiento y fe, el derecho a poseer propiedades y a cerrar contratos justos, y el derecho a la justicia" (Marshall, 1950: 10-11).

El periodo formativo para los derechos políticos comenzó entonces en el siglo XIX. Esto pudo tener lugar únicamente después de que "los derechos civiles vinculados al estatus de libertad ya habían adquirido sustancia suficiente como para justificar el que habláramos de un estatus general de ciudadanía” (Marshall, 1950: 19). Las garantías efectivas de los derechos civiles fundamentales fueron vistas por Marshall como un prerrequisito esencial para los derechos políticos de ciudadanía. Sin el nuevo estatus creado de "ciudadano", los derechos políticos independientes del estatus económico eran inconcebibles. Los derechos civiles, en efecto, crearon la nueva pauta para evaluar los derechos políticos. Esto se debe a que, a diferencia de la creación de nuevos derechos civiles durante el siglo anterior, la evolución de los derechos políticos de ciudadanía implicaba el "otorgamiento de viejos derechos a nuevos sectores de la población... Los derechos políticos fueron imperfectos, no en su contenido, sino imperfectos en su distribución, esto es, de acuerdo con los estándares de la ciudadanía democrática” (Marshall, 1950: 19). La transformación industrial y la nueva concepción de los derechos civiles volvieron cada vez más obsoletas a las viejas concepciones de los derechos. El proceso de consolidación de los derechos políticos de ciudadanía tomaría aproximadamente cien años. Culminó con el Acta Británica de Reforma en 1918, cuando los derechos políticos se vincularon por vez primera de manera directa a la ciuda- 
danía con la adopción del sufragio universal del hombre, independientemente de su estatus económico personal. ${ }^{6}$

Con los derechos políticos extendidos a todos los adultos (varones), la evolución de los derechos de ciudadanía culminó entonces, según Marshall, con la suma de los derechos sociales de ciudadanía. Una vez que los obreros tienen el derecho al voto, esto se traduce en nuevas políticas sociales que comienzan a estrechar de manera directa la brecha entre el ingreso real y el ingreso monetario (i.e., entre el nivel de vida real de una persona, incluyendo los subsidios del Estado, y su salario real). Para Marshall, el decremento de la desigualdad social debido al desarrollo económico, combinado con la integración social conseguida a través de los derechos universales cívicos y políticos de ciudadanía, generó un nuevo consenso social acerca de la minimización, si no de la abolición, de la desigualdad social a través de la adopción de los nuevos derechos de ciudadanía. Nació así el moderno Estado de bienestar:

La integración social se propagó de la esfera del sentimiento y del patriotismo a aquella del disfrute material. Los componentes de una vida civilizada y cultivada, anteriormente monopolio de unos cuantos, fueron progresivamente colocados al alcance de muchos, quienes se vieron así motivados a extender las manos hacia aquellos que aún eludían su abrazo. La disminución de la desigualdad fortaleció la demanda de su abolición, al menos respecto a los aspectos esenciales del bienestar social (Marshall, 1950: 47).

Para Marshall, con el coronamiento de los derechos sociales, la ciudadanía estaba completa. Este proceso histórico de 300 años parece, (al menos en retrospectiva) un círculo virtuoso en el cual los derechos acumulativos de los grupos subalternos continuaron creciendo al punto que en las democracias liberales consolidadas se alcanzó un clásico "compromiso democrático de clase" entre los representantes de las grandes empresas y los trabajadores (Przeworski, 1985). La desigualdad social no fue eliminada, pero fue significativamente reducida hasta el punto que "la ciudadanía en sí misma se convirtió, en cierto sentido, en el artífice de la legítima desigualdad social” (Marshall, 1950: 9).

${ }^{6}$ Como hace notar Marshall, "el estatus de la mujer, o al menos de la mujer casada, era peculiar al menos en ciertos aspectos importantes" (Marshall, 1950: 18). En primer lugar, los derechos civiles, y más tarde los derechos políticos de ciudadanía disfrutados por todos los 'ciudadanos' estaban, muy entrado el siglo veinte, limitados en su alcance a los varones adultos. Sin embargo, sorprendentemente Marshall no menciona esta disminución de la naturaleza universal de los derechos ciudadanos, ni incluye en el análisis de su evolución la eventual eliminación de las barreras de género para su completo ejercicio. 
Hoy es claro que la evolución de la ciudadanía no culminó con la adopción de los derechos sociales de ciudadanía. Precisamente como Marshall (1950: 29) señalara, cada sociedad debe desarrollar su propio ideal de ciudadanía porque "no existe esencia universal que determine cuáles deben ser esos derechos y obligaciones". La misma combinación "ideal" de derechos civiles, políticos y sociales de ciudadanía que él describió está enfrentando actualmente numerosos desafíos. Los derechos sociales han sido cada vez más atacados en prácticamente todas las democracias consolidadas, incluyendo Gran Bretaña, lo que sugiere una reversibilidad que nunca fue anticipada por Marshall (Turner, 1992). Hoy en día, la visión casi idílica de Marshall acerca de las relaciones de clase resulta anacrónica para América Latina, en donde los conflictos sociales parecen ser de una naturaleza muy diferente.

Más aún, como teoría causal de los derechos de ciudadanía, el ensayo de Marshall es inadecuado de muchas maneras. A pesar de algunas referencias aisladas, ${ }^{7}$ se ignora significativamente el papel del conflicto de clases y de las luchas sociales en la definición y expansión de los derechos ciudadanos (Rees, 1996; Steinberg, 1996; Turner, 1992; Roberts, 1996). Mientras que esta explicación de la ciudadanía se refiere explícitamente a las relaciones de clase, no es un argumento estructuralista, o que siquiera asuma los intereses contradictorios de clase. En vez de ello, Marshall adopta una postura determinista, casi funcionalista, de la evolución de los derechos de ciudadanía desde la perspectiva del desarrollo económico capitalista y la estabilidad política. Subyace el presupuesto fundamental de que los intereses de la clase trabajadora y de los capitalistas son complementarios más que contradictorios. En primera instancia, los capitalistas requerían de los derechos civiles para proteger sus intereses. Esto, a su vez, es retratado por el autor como si desatara un proceso teleológico aparentemente inevitable por medio del cual el desarrollo económico creó un nuevo consenso societal alrededor de los derechos universales de ciudadanía. La institucionalización de los derechos ciudadanos pudo ir a la par de las cambiantes actitudes públicas, en gran medida porque la continua prosperidad económica era en sí misma responsable de los crecientes niveles de igualdad

\footnotetext{
${ }^{7}$ Por ejemplo, cuando apunta que la ciudadanía se basa no únicamente en la "lealtad hacia una civilización que es posesión común... Su crecimiento es estimulado por la lucha por ganar aquellos derechos y por su disfrute una vez que se han ganado" (Marshall, 1950: 41).
} 
económica, independientemente de las políticas redistributivas del Estado. En última instancia, la prosperidad económica y el nuevo consenso social que ésta creó permitieron un ataque directo cada vez mayor por parte del Estado hacia cualquier causa persistente de desigualdad social. Pero estas políticas debían esperar su momento. Por lo tanto, un esfuerzo temprano por garantizar derechos sociales a través de la Ley Británica de los Pobres a finales del siglo XVIII estaba condenado al fracaso "porque era totalmente ofensivo para el espíritu que prevalecía en la época" (Marshall, 1950: 23). El determinismo económico de Marshall y su enfoque de un único camino para el desarrollo de los derechos universales de ciudadanía anticipó de muchas maneras las teorías de la modernización del desarrollo económico de las décadas de 1960 y 1970. De manera similar, estas teorías vislumbraban una única vía hacia el desarrollo, libre de conflictos y más o menos inevitable, con base en las experiencias de las primeras naciones industrializadas de Occidente (Lipset, 1959; Deutsch, 1961; Almond et al., 1973; Huntington, 1971; y Portes, 1974).

Sin embargo, es importante enfatizar que, a diferencia de las teorías de la modernización, la descripción de Marshall acerca de la evolución de los derechos ciudadanos en Gran Bretaña no es necesariamente inconsistente con los enfoques que enfatizan el papel del conflicto y la contingencia en la construcción social de la ciudadanía. ${ }^{8}$ Es posible que los capitalistas británicos hayan gozado de prosperidad económica y de una relativa estabilidad política durante décadas, pero esto se entiende más como la consecuencia de las concesiones logradas como resultado de las luchas sociales iniciadas por los obreros, más que como el resultado de una predeterminada teleología del desarrollo capitalista (Bendix, 1964; Przeworski, 1985). De manera similar, los capitalistas en otros lugares lo han hecho extraordinariamente bien siguiendo distintos caminos de desarrollo político y económico, en los cuales un reducido número de derechos sociales de ciudadanía fueron efectivamente otorgados a los obreros como una manera de cooptar y controlar su movilización ante la ausencia de derechos políticos y civiles efectivos (Mann, 1996; Oxhorn, 1995b y 1998b).

Más que resultado de los requerimientos funcionales del capitalismo, o consecuencia de un nuevo consenso social asociado con la modernidad, sostengo que una teoría causal de los de-

${ }^{8}$ Véase Tilly (1996a) para una serie de casos de estudio recientes en torno a la construcción histórica de la ciudadanía. Véase también Foweraker y Landman (1997). 
rechos de ciudadanía en Gran Bretaña o en cualquier otro lugar es más comprensible en términos del desarrollo de la sociedad civil al interior de países particulares, y de su interacción con el estado. Para los propósitos de esta argumentación, la sociedad civil se define como: el tejido social formado por una multiplicidad de unidades funcionales territorialmente autoconstituidas que coexisten de manera pacífica y que de manera colectiva ejercen resistencia a la subordinación al Estado, al mismo tiempo que exigen ser incluidas en las estructuras políticas nacionales. ${ }^{9}$

Esta definición centra la atención en las relaciones de poder en el interior de una sociedad dada, y enfatiza la centralidad de la organización y de la lucha. Contrasta con un enfoque más liberal centrado en los individuos y en las normas asociadas con una cultura política democrática. ${ }^{10}$ La dinámica dual de resistencia e inclusión que caracteriza a las sociedades civiles implica que las sociedades civiles fuertes reflejan una relativa dispersión del poder político en el interior de los gobiernos. ${ }^{11}$ La habilidad de los diversos grupos para organizarse contribuye a la dispersión del poder político a su favor, y evita o disminuye la tendencia en las sociedades capitalistas de que los intereses de los actores y clases sociales dominantes subordinen por completo los intereses de otros actores y clases sociales menos poderosos. Si bien la sociedad civil requiere del espacio que sólo un régimen político democrático puede proporcionarle para su cabal desarrollo, su surgimiento ha precedido históricamente al advenimiento de los

\footnotetext{
${ }^{9}$ Desarrollo esta definición como parte de lo que llamo enfoque colectivista para la comprensión de la sociedad civil. Esto contrasta con una perspectiva más liberal orientada hacia los intereses individuales y los valores normativos dominantes dentro de una sociedad determinada, como la confianza y la cultura cívica. (Véanse Oxhorn, 1995a y 1995b.) Es importante enfatizar que las perspectivas colectivista y liberal destacan distintos aspectos de la moderna sociedad civil (Black, 1984; Taylor, 1990). He adoptado la perspectiva colectivista porque centra su atención en aquellos aspectos de la sociedad civil que son centrales para la comprensión de la ciudadanía como un evento contingente y socialmente construido que puede desarrollarse por caminos diferentes.

${ }^{10}$ Hasta cierto punto, esta perspectiva liberal acerca de la sociedad civil adopta muchos de los mismos presupuestos que subyacen en la discusión de Marshall. Las limitaciones de esa perspectiva acerca de la sociedad civil se ven reflejadas de manera similar en las limitaciones del análisis de Marshall en tanto teoría causal de la ciudadanía.

${ }^{11}$ Los términos poder y recursos de poder se emplean aquí para hacer referencia sobre todo a los recursos económicos y a la capacidad organizativa para definir y defender de manera autónoma los intereses colectivos de grupo. Esto último puede basarse en un fuerte sentido de identidad colectiva, ideología y habilidad organizativa o knowhow. Puede también derivarse de la disponibilidad de incentivos selectivos para sus miembros. El poder físico o la fuerza de coerción no son relevantes aquí, ya que éstos son generalmente empleados para fines antitéticos al desarrollo y el mantenimiento de las sociedades civiles.
} 
regímenes democráticos estables y es, por lo tanto, hasta cierto punto independiente de la existencia de éstos (Oxhorn, 1995a y 1995b). De hecho, la fuerza de la sociedad civil es, en primera instancia, un factor importante para el logro de las transiciones a la democracia (O'Donnell y Schmitter, 1986). En las sociedades en donde el poder político está más concentrado, la sociedad civil es más débil y las posibilidades de estabilidad democrática y desarrollo equitativo a largo plazo son, en consecuencia, menores.

Al centrar la atención en las relaciones de poder, queda claro de qué manera la sociedad civil como concepto es diferente de la estructura económica. En particular, la sociedad civil se caracteriza más por un "pluralismo societal institucionalizado" (Schmitter, 1986: 6) que por la relativa fuerza de organizaciones funcionales de clase, como los grupos de empresarios, los sindicatos y las organizaciones campesinas. Además de las clases sociales, otros actores en la sociedad civil pueden incluir a los sectores económicos y a las profesiones, a las comunidades territoriales independientes, los grupos étnicos y lingüísticos, las religiones y las sectas, las asociaciones voluntarias, las agrupaciones generacionales y de género, entre otras. Las identidades compartidas, la habilidad de autoorganización e incluso una historia de lucha colectiva son fuentes de poder que permiten a los grupos en desventaja desafiar el status quo (Brenner, 1976; Evers, 1985; Jelin, 1990; Calhoun, 1991; Subramanian, 1995; Offe, 1987; Melucci, 1985).

Si bien la sociedad civil es diferente de la estructura económica, la estructura económica condiciona el potencial de la sociedad civil de maneras importantes. Puesto que el cambio económico contribuye a una mayor dispersión de los recursos de poder e incrementa la capacidad de los diversos grupos para organizarse, debería facilitar mayores niveles de inclusión social y democratización. ${ }^{12}$ Por el contrario, si el cambio económico incrementa el nivel de la concentración económica, o si va acompañado de la edificación de nuevas barreras para la acción colectiva por parte de distintos grupos, tendería a minar a la sociedad civil y a favorecer una mayor contracción de la inclusión social y la democratización.

${ }^{12}$ Por democratización me refiero a la extensión de los procesos democráticos de toma de decisiones a diferentes esferas. (Véase Schmitter and Karl, 1991.) 
Históricamente, como menciona Tilly (1996b: 9), fue la "lucha y la negociación entre los estados en expansión y sus sujetos [lo que] creó la ciudadanía ahí en donde no había existido previamente". Si bien hoy en día probablemente hay mayor consenso que nunca antes respecto al contenido normativo de los derechos democráticos ciudadanos, en la práctica los derechos son aún rebatidos. Más todavía, aún no existe consenso acerca de la puesta en práctica de derechos específicos de ciudadanía ni respecto a cómo hacerlo. En la mayor parte de las nuevas democracias, los conflictos acerca de los derechos fundamentales de ciudadanía fueron a menudo temas centrales, aunque no resueltos, durante el proceso de transición. El fracaso de las instituciones democráticas para manejar estas deficiencias después de la transición es con frecuencia, como se discute detalladamente más adelante, la principal fuente de fragilidad para muchos de los nuevos regímenes democráticos. La administración, tanto históricamente como en nuestros días, es clave para comprender cómo los derechos ciudadanos evolucionan o se estancan. Las presiones para la expansión de los derechos ciudadanos que surgen (o dejan de surgir) en el interior de la sociedad civil, y la forma como esas presiones son manejadas por los actores estatales son puntos centrales para cualquier teoría causal de la ciudadanía.

Desde la perspectiva del papel de la sociedad en la construcción de la ciudadanía, es importante resaltar tres aspectos centrales de la comprensión de Marshall acerca de la ciudadanía y la democracia en Gran Bretaña. Primero, la desigualdad económica debe manejarse de manera sistemática puesto que es tanto inevitable dentro del capitalismo, como contraria a las normas democráticas. Esto no significa, como enfatizó Marshall, que la desigualdad deba ser eliminada. Semejante esfuerzo sería aún más antitético a la práctica democrática. En lugar de ello, la desigualdad económica debe disminuir paulatinamente, como fue el caso en Gran Bretaña durante el periodo en el cual los derechos ciudadanos evolucionaron. ${ }^{13}$ La desigualdad económica prevaleciente debe ser continuamente legitimada, algo que inicialmente se consiguió en Gran Bretaña mediante la promulgación de los derechos universales de ciudadanía. En esencia, los derechos ciudadanos deben orientarse a asegurar que "la civilización unificada

\footnotetext{
${ }^{13}$ Esta observación también es consistente con un largo cuerpo de evidencia empírica que demuestra que existe una relación positiva entre la longevidad de los gobiernos democráticos y la disminución gradual de la desigualdad económica. (Véanse Przeworski et al., 1996, y Przeworski et al., 1995.)
} 
que hace aceptables las desigualdades sociales, y que amenaza con volverlas económicamente disfuncionales, se logra mediante un progresivo divorcio entre los ingresos reales y los monetarios" (Marshall, 1950:81).

El segundo aspecto que merece ser resaltado en torno a la discusión de Marshall acerca de los derechos ciudadanos se refiere al contenido diferencial, o calidad, de los derechos ciudadanos. A menudo se asume que la ciudadanía es un todo integral una propuesta de todo o nada, independiente de su sustancia real. A través del nacimiento o de la naturalización, aquellos que son 'ciudadanos' son vistos como poseedores de los mismos derechos y presumiblemente comparten las mismas obligaciones como parte de una nación definida por sus fronteras geográficas y por una 'comunidad imaginaria' (Cfr. Anderson, 1991). Las distinciones de jure de la "ciudadanía de segunda clase" no son ya normativamente justificables. Marshall nos recuerda tanto que la ciudadanía es estratificada, como que necesitamos comprender las relaciones entre esos estratos. Para el caso específico de Gran Bretaña, la secuencia por la cual estos estratos fueron sumados a la significación de ciudadanía fue particularmente fortuita. Como se discute abajo, las secuencias alternativas probablemente tienen importantes consecuencias para el mantenimiento de las políticas democráticas.

La distinción es particularmente importante en América Latina, en donde las identidades nacionales fueron definidas mientras eran incorporadas, en ausencia de la bondadosa movilización de masas característica del nacionalismo europeo (Anderson, 1991; Lynch, 1973). Gradualmente surgirían concepciones alternativas de los derechos de ciudadanía que eran en gran medida independientes de los derechos políticos y civiles discutidos por Marshall, centradas principalmente en vagas nociones de los derechos sociales de ciudadanía (O’Donell, 1979). La movilización nacionalista no se extendería por la región sino hasta el siglo $\mathrm{xx}$, cuando se encontraba desconectada casi por completo de cualquier noción de derechos ciudadanos universales. En la mayoría de los casos, ello fue consecuencia de exitosos liderazgos populistas cuyo compromiso con las normas democráticas de ciudadanía universal era, cuando menos, ambiguo (Oxhorn, 1998a). Algunos derechos ciudadanos importantes, derechos sociales en particular, fueron intencionalmente segmentados y eran a menudo otorgados por regímenes autoritarios como una forma de co- 
optar y controlar las presiones sociales, punto al que regresaré más adelante. ${ }^{14}$

Finalmente, la dimensión colectivista de los derechos ciudadanos es central para entender cómo la ciudadanía se relaciona con la desigualdad social. Si bien los derechos ciudadanos son obviamente derechos individuales, las luchas que los definen sólo pueden llevarse a cabo de manera colectiva, y las demandas colectivas de derechos ciudadanos son esenciales para hacer efectivos esos derechos. Hay una cierta paradoja en esta observación: el ideal liberal de la libertad individual, tan cercanamente asociado con el ideal de ciudadanía universal, no puede lograrse a menos que los individuos se organicen colectivamente para demandar respeto a los derechos que tal libertad conlleva. Como resultado, estos derechos 'individuales' son efectivamente garantizados a distintos grupos (por ejemplo, trabajadores, mujeres, analfabetos, entre otros), aun cuando su justificación normativa descanse sobre premisas liberales. Marshall (1950: 42 y 43) reconoció esta paradoja, apuntando que "los derechos civiles fueron en su origen intensamente individuales, y esa es la razón por la que armonizaron con la fase individualista del capitalismo...[aunque] los grupos fueron habilitados para actuar legalmente como individuos", en particular los sindicatos. De esta manera, "uno de los principales logros del poder político a finales del siglo XIX fue el reconocimiento del derecho de negociación colectiva. Esto significa que se buscaba el progreso social mediante el fortalecimiento de los derechos civiles...”. Los derechos civiles son, en la práctica, derechos colectivos, independientemente de la intención de los reformistas liberales.

La dimensión colectivista de los derechos de ciudadanía es de muchas maneras la esencia de las sociedades civiles fuertes. Lo que distingue a la sociedad civil de otras formaciones sociales es la naturaleza de sus actores colectivos, y sus demandas u objetivos específicos. Un buen ejemplo de esto es la clase obrera. En las

${ }^{14}$ Es importante puntualizar que no todos los derechos sociales fueron otorgados por las élites con el propósito específico de cooptar a las organizaciones obreras u otros grupos sociales clave. En muchos casos, incluyendo el de Chile durante la mayor parte de este siglo, tales derechos fueron resultado de prologadas luchas políticas. Incluso en México, un país en donde la cooptación de amplios sectores de la población ha sido considerado el sello distintivo de la estabilidad política del régimen, los contornos precisos de estos 'derechos' fueron a menudo determinados a través de luchas que involucraron a grupos organizados de la sociedad. (Véanse Vaughan, 1997; Rubin, 1977 y Middlebrook, 1995.) Con todo, esos derechos fueron significativamente limitados por procesos de inclusión controlada en los que todos los actores subalternos fueron involucrados, punto al que regresaré más adelante. 
sociedades que han experimentado un mínimo nivel de industrialización, la clase obrera es un actor potencial importante. Si la clase obrera organizada será o no parte de la sociedad civil, dependerá de cómo se organice el movimiento y de sus metas. En la Europa Occidental del siglo XIX y en América Latina en general, la clase obrera organizada fue un actor clave en los tempranos procesos de democratización (Bendix, 1964; Rueschemeyer, Stephens y Stephens, 1992; Collier y Collier, 1991). Sólo en muy raras ocasiones la clase obrera se ha organizado como fuerza revolucionaria. En vez de ello, como señala Bendix (1964) para Europa Occidental, los movimientos socialistas (y nacionalistas) del siglo XIX deben verse como movimientos políticos, que reflejan la alineación política de la clase obrera al buscar la integración al sistema sociopolítico:

Más que comprometerse en una búsqueda milenaria de un orden social, las masas recientemente politizadas protestaron contra la ciudadanía de segunda clase, exigiendo el derecho de participación en términos de igualdad al interior de la comunidad política del estado-nación. (Bendix, 1964: 73)

En América Latina, las demandas de integración de la clase obrera al sistema sociopolítico han sido históricamente mucho menos exitosas, como resultado de los procesos de inclusión controlada (Oxhorn, 1995b y 1998b). En muchos países, la clase obrera fue organizada por el Estado para limitar su poder económico y político al minar cualquier forma de organización autónoma que pudiera efectivamente desafiar la posición privilegiada de las clases dominantes. Esto fue una clave característica del populismo latinoamericano y de las instituciones corporativas de países como Brasil y México. En algunos casos, de manera más notable en Chile, surgió un movimiento obrero fuerte y autónomo, vinculado muy de cerca a los partidos de izquierda. ${ }^{15}$ Pero incluso en estos casos, el desarrollo de la sociedad civil fue restringido por las clases dominantes que continuaban controlando efectivamente al Estado.

${ }^{15}$ La relativa fuerza de la sociedad civil en Chile, comparada con cualquier otra de la región, se refleja también en la singular evolución de los derechos políticos y sociales de ciudadanía en el contexto del subdesarrollo económico. Como es mencionado por Garretón (1989), la estabilidad democrática de alrededor de 1930 hasta el golpe militar de 1973 dependió de la expansión simultánea de la democracia política (por ejemplo, los derechos políticos), de la democratización sustantiva (por ejemplo, los derechos sociales) y del desarrollo económico basado en un modelo de industrialización por sustitución de importaciones. 
A lo largo de toda América Latina surgió la sociedad civil, pero ésta permaneció débil y a merced del Estado. Cuando las instituciones de inclusión controlada fracasaron en su intento por limitar las demandas de integración de la clase obrera, el gobierno autoritario se impuso en países tan diversos como Argentina, Brasil, Chile y Uruguay. Ahí en donde las instituciones de inclusión controlada no se resquebrajaron -de manera más notable en el autoritario México y en la democrática Venezuela-, la sociedad civil permaneció adormecida y la clase obrera organizada se convirtió en un actor privilegiado comparado con la amplia mayoría.

América Central (a excepción de Costa Rica), la Bolivia prerrevolucionaria, Cuba y México, así como el Paraguay de Stroessner y Perú antes del gobierno militar de 1968, fueron excepciones importantes al patrón generalizado de inclusión controlada. En estos casos, la inclusión del sector popular fue mínima, si no inexistente, y la sociedad civil permaneció igualmente débil. La concentración resultante del poder político y económico llevó a extremos de polarización social, aún para los estándares de América Latina. Bajo estas circunstancias, parecía inevitable un estallido social. Ante la falta de otras vías para lograr una integración efectiva al sistema sociopolítico, debido a los con frecuencia altos niveles de represión, la clase obrera se alió con el aún más numeroso campesinado para integrar poderosos movimientos revolucionarios. En diversos grados y con diferentes niveles de éxito, ${ }^{16}$ estos movimientos llegaron a representar a actores fuertes y bien organizados del sector popular, pero sus objetivos y métodos no eran compatibles con los de la sociedad civil.

El surgimiento de estos movimientos refleja, fundamentalmente, la debilidad de la sociedad civil y la concomitante falta de alternativas al conflicto político para responder a los intereses del sector popular. ${ }^{17}$ Esto puede verse de manera más clara en aquellos casos en que los movimientos revolucionarios han fra-

\footnotetext{
${ }^{16}$ Esta alianza de campesinos-trabajadores fue más exitosa en Cuba. Su éxito es más ambiguo en otros casos. En Nicaragua y Bolivia, el triunfo revolucionario demostró ser de corta duración. La Revolución Mexicana fue posible gracias a esta alianza, pero los campesinos y los trabajadores pronto vieron sus intereses subordinados a los de actores más poderosos en el control del Estado revolucionario. El miedo a una alianza revolucionaria exitosa llevó al ejército peruano a iniciar el golpe de Estado de 1968 e inició las amplias reformas que eliminaron a la oligarquía como clase social y aceleraron el incipiente proceso de industrialización por sustitución de importaciones en el país.

${ }^{17}$ Es importante enfatizar que los objetivos y los métodos de estos actores revolucionarios pueden cambiar, como ha sido el caso del Frente Farabundo Martí para la Liberación Nacional (FMLN) en El Salvador. Por una diversidad de razones, los cambios tan dramáticos son, sin embargo, bastante raros (Karl, 1992).
} 
casado en conseguir un apoyo popular sustancial (WickhamCrawley, 1989). ${ }^{18}$ De manera similar, cuando las élites estatales en Colombia crearon una organización nacional campesina como mecanismo de cooptación e inclusión controlada, el limitado espacio que esto otorgó a la participación popular dio como resultado una oleada de apoyo que permitió a la organización la obtención de cierta autonomía con respecto al Estado para desafiar las políticas estatales contrarias a los intereses de los miembros de la organización. Sin embargo, cuando un nuevo y más radical liderazgo revolucionario tomó control de la organización, los subsecuentes conflictos con las raíces más moderadas de ésta minaron su fuerza y destruyeron su habilidad para actuar como interlocutor autónomo de los campesinos frente al Estado (Zamosc, 1989). Incluso una mínima redistribución del poder económico y político asociado con las organizaciones emergentes de la sociedad civil y con su interacción con el Estado parecería ser preferible a los altos riesgos -y aún a los altos costos- asociados con la lucha revolucionaria armada en la gran mayoría de los sectores populares.

Mientras que la discusión de los derechos y la acción colectiva ha sido limitada a las clases sociales, no hay razón por la que el análisis no sea igualmente aplicable a la comprensión de otros actores potenciales. Como ya se ha señalado, la ciudadanía es una construcción social en la que participan -o deberían participar potencialmente- una variedad de actores. Entre éstos pueden contarse, además de las clases sociales, los grupos basados en el género, la etnicidad, la religión, las prácticas sexuales, la edad, la identidad cultural, etcétera. Ellos son los que conforman en esencia los elementos de las sociedades civiles fuertes. Su ausencia de los procesos políticos nacionales puede ser un reflejo de la debilidad de la sociedad civil y/o de las políticas represivas del Estado, lo que desemboca de manera inevitable en la limitación de los derechos ciudadanos.

En suma, la expansión de la ciudadanía para incluir los derechos civiles, políticos y en esencia los derechos sociales, como describe Marshall, debe ser reinterpretada para reconocer la naturaleza conflictiva del proceso, así como el papel central que

\footnotetext{
${ }^{18}$ Esto también explica porque los movimientos como Sendero Luminoso en Perú a menudo atacaron de manera brutal a las organizaciones populares y a otros actores del sector popular, por no mencionar a las instituciones de participación democrática del Estado. En efecto, Sendero buscó de manera deliberada socavar a la sociedad civil de Perú y eliminar cualquier alternativa que no fuera la revolución violenta.
} 
jugó la sociedad civil al interactuar con el Estado británico. Al mismo tiempo, tales luchas son constitutivas de la creciente fuerza de la sociedad civil. A través de la lucha colectiva, las identidades colectivas se crean y redefinen como nuevas fuentes de poder político (Hobson y Lindhholm, 1997). Cuando los derechos se otorgan como resultado de una lucha social, el Estado reconoce e institucionaliza una distribución previa de los recursos de poder, lo que contribuye a una mayor dispersión de estos recursos y fortalece, en consecuencia, a la sociedad civil.

Desde esta perspectiva, el camino seguido por Gran Bretaña y tan elocuentemente descrito por Marshall puede aún ser 'ideal', pero es también singular. Esta es en esencia la conclusión a la que llega Barrington Moore (1996), quien discute que el camino de Gran Bretaña hacia la democracia, aunque marcado por una considerable violencia, fue menos problemático que en otros lugares debido a la temprana comercialización de la agricultura. Según Moore, la comercialización de la agricultura eliminó al campesinado como clase que pudiera ser movilizada, ya sea por fuerzas de reacción o revolucionarias. Asimismo, creó una burguesía capaz de constituirse en un aliado más o menos equivalente de la aristocracia para crear un balance efectivo contra el Estado y frenar las tendencias autoritarias de este último. En términos del desarrollo de la sociedad civil, el temprano ingreso en el mercado con la comercialización de la agricultura creó nuevos recursos de poder distribuidos de manera más amplia. ${ }^{19}$ Como señala Moore, esto incrementó de manera clara el poder de la burguesía.

De igual importancia, estos nuevos recursos eran en gran medida independientes del Estado (aunque éste jugó un papel crucial en la regulación de los nuevos mercados, y facilitó el incremento de las relaciones comerciales de Gran Bretaña). Junto con la temprana industrialización, hubo también un aumento significativo en el poder potencial de la clase obrera, lo que se vio reflejado en su cada vez mayor tasa de ingresos. También fue el resultado (como Marx lo apreció anteriormente) de la relativa facilidad para organizar a los obreros que estaban concentrados en las fábricas, quienes compartían marcados intereses comunes

${ }^{19}$ Por esta razón, algunas veces se ve a la sociedad civil como si persiguiera los mismos fines que el mercado. 
y cuya cooperación se estaba volviendo cada vez más indispensable para la acumulación continua de capital. ${ }^{20}$

Cuando la evolución de los derechos ciudadanos se lleva a cabo por caminos alternativos, las consecuencias para la democracia y la sociedad civil son a menudo dramáticas. Por ejemplo, los derechos sociales de ciudadanía a menudo han sido, a lo largo de la historia, un sustituto de los derechos civiles y políticos. Mann (1996) critica tanto la teleología como el funcionalismo del análisis de Marshall, al señalar que esto es precisamente lo que ocurrió en la Alemania de Bismarck. Incluso va más lejos al sugerir que semejante sistema de integración social habría resultado bastante duradero de no haberse atravesado la Primera Guerra Mundial. Desde la perspectiva de la sociedad civil, la integración social en la Alemania de Bismarck es muy similar a los procesos de inclusión controlada comunes en América Latina. Con una temprana llegada al proceso de industrialización, una clase obrera pequeña y relativamente débil pudo ser integrada al sistema político de una manera subordinada que obstaculizó el desarrollo subsecuente, tanto de los derechos ciudadanos como de la sociedad civil. Más que simplemente terminar con este experimento de control social efectivo, la Primera Guerra Mundial marcó el inicio de una nueva era a medida que la industrialización continuaba su progreso. La clase obrera no sólo seguía creciendo, sino que también fue movilizada como parte de la fuerza de guerra. Con la derrota de Alemania en la Segunda Guerra Mundial, se crearon nuevas estructuras corporativas, como en la mayor parte de Europa Occidental, que dieron expresión institucionalizada, por parte del Estado, a la fuerza preexistente de las organizaciones obreras, y de hecho en ese proceso la fuerza se incrementó. El resultado final fue la consolidación de un nuevo conjunto de derechos ciudadanos que incorporaron por completo a los derechos civiles, políticos, y particularmente a los derechos sociales ciudadanos de alto nivel.

En América Latina, el corporativismo en la región (así como en otras regiones en vías de desarrollo) fue visto como parte de una estrategia de "modernización defensiva desde arriba" (Schmitter, 1974). Desde aproximadamente la década de 1930 hasta la década de 1940, en países tan diversos como Argentina, Brasil

\footnotetext{
${ }^{20}$ Estas son quizás ventajas únicas de la clase obrera tradicional comparada con otros grupos en desventaja en el interior de la sociedad, particularmente con los campesinos, y son las principales razones por las que los derechos de la clase obrera estuvieron entre los primeros en ser institucionalizados en la mayor parte de los países.
} 
y México, las élites que controlaban el Estado impusieron a los obreros una estructura estatal que sería usada para controlar las demandas y la movilización obreras. El Estado creó instituciones jerárquicas del trabajo que no tenían raíces efectivas en la sociedad civil para mantener la estabilidad política y promover el crecimiento económico, ante la ausencia de instituciones o medidas comprensivas de bienestar social que se dirigieran a la creciente desigualdad en el ingreso. Más que redistribuir el poder a favor de la clase obrera, como ocurrió en Europa Occidental, el corporativismo en América Latina institucionalizó las desigualdades de clase en términos del acceso al Estado y a los recursos económicos, al crear un nuevo y relativamente pequeño grupo privilegiado de obreros en los sectores populares. En lugar de permitir la articulación autónoma de las demandas obreras en el marco de un Estado democrático liberal, las asociaciones corporativistas en América Latina siguieron siendo dependientes y penetradas por el Estado, lo que frenó el crecimiento de la sociedad civil.

En contraste, en Chile (y en Argentina, después del derrocamiento de Perón en 1955), las organizaciones obreras tenían profundas raíces en la sociedad, lo que les permitió obtener una considerable autonomía del Estado en términos de su habilidad para movilizar obreros y presionar al mismo. Si bien la autonomía y la fuerza de las organizaciones obreras no rivalizaron con sus contrapartes europeas, ${ }^{21}$ como resultado de luchas históricas, los derechos ciudadanos de los obreros chilenos (y al menos los derechos sociales, si no políticos, de los obreros argentinos) fueron mucho mayores que los de los obreros en la mayor parte del resto de los países latinoamericanos. La relativa fuerza de los obreros en ambos países, por otra parte, fue un factor fundamental que contribuyó a los golpes que dieron origen a las dictaduras militares en las décadas de 1960 y 1970 cuando las demandas hechas al Estado excedieron los límites establecidos por los procesos de inclusión controlada. ${ }^{22}$

El mismo punto fundamental acerca de la secuencia de los derechos de ciudadanía y del desarrollo de la sociedad civil des-

${ }^{21}$ En Chile, la autonomía del trabajo estuvo significativamente circunscrita por los partidos políticos de izquierda, particularmente por el Partido Comunista, que buscaba movilizar a los obreros para tomar control del Estado. La autonomía del trabajo en Argentina estuvo limitada de manera similar por sus estrechos vínculos con el movimiento peronista.

22 También es posible que Alemania hubiera tenido el primer estado burocrático autoritario de haber continuado durante el siglo xx las políticas de integración social establecidas por Bismarck. (Véase O’Donnel, 1979.) 
taca, de manera diferente, al examinar el destino de los derechos de la mujer en la antigua Unión Soviética y en la Europa Oriental postsoviética. ${ }^{23}$ Como es bien sabido, los derechos sociales de las mujeres en el comunismo soviético eran a menudo muy avanzados en términos de su potencial para otorgar poder a la mujer en relación con el hombre. De hecho, el orden comunista a menudo pretendió defender muchos derechos de las mujeres (sin importar cuan efectivas o genuinas fueran en realidad esas pretensiones); lo que constituye parte del problema. El otorgamiento de tales derechos por parte del Estado comunista ante la ausencia de cualquier demanda autónoma de éstos desde la sociedad civil, frenó el desarrollo de esta sociedad civil al agotar de antemano el potencial para la movilización de la mujer. ${ }^{24}$ Cuando los regímenes comunistas cayeron, se agregó un nuevo estigma a los movimientos feministas debido a que sus demandas estaban tan estrechamente asociadas con los ahora desacreditados comunismos. Frente a considerables reveses en los derechos que hubieran sido considerados triunfos mayores para las mujeres, de haber sido conseguidos en otros contextos (acceso a servicios culturales y de salud, derecho al aborto y a los anticonceptivos, por mencionar sólo algunos), uno se topa con una "narrativa cultural que ratifica una mujer esencialmente sexualizada, que busca reivindicar su domesticidad natural que le había sido negada por el régimen anterior" (Hobson y Lindholm, 1997: 501).

\section{Los derechos ciudadanos en las nuevas democracias de América Latina}

En contraste tanto con la explicación teleológica de Marshall acerca de los derechos ciudadanos, como con el patrón alternativo de los derechos sociales que preceden a los derechos políticos y civiles de ciudadanía, las recientes transiciones a la democracia en América Latina representan un tercer camino alternativo: la dotación de derechos políticos universales de ciudadanía en ausencia de derechos civiles universales y ante el declive de los derechos sociales. Aunque estables en general (al menos hasta

${ }^{23}$ Lo que sigue está basado en Waylen (1994) y Einhorn (1989 y 1991). Véanse también Hobson y Lindholm (1997).

${ }^{24}$ La represión jugó un papel, obviamente, pero sería demasiado simple sugerir que la debilidad de los movimientos de mujeres en el antiguo bloque soviético se debió únicamente a esto. En América Latina, los movimientos de mujeres alcanzaron niveles considerables de movilización bajo regímenes militares bastante represivos. (Véanse, por ejemplo, Jacquete, 1989; Álvarez, 1990.) 
ahora), ${ }^{25}$ estos regímenes democráticos se caracterizan por las grandes limitaciones en la calidad del gobierno democrático, lo que representa grandes desafíos para su eventual consolidación. Esta secuencia única refleja tanto la naturaleza elitista de estas transiciones, sobre las que los militares han mantenido una desproporcionada influencia, como las consecuencias de las políticas económicas neoliberales. Ambas cosas han afectado la capacidad de la sociedad civil para comprometerse con el tipo de luchas colectivas que son necesarias para definir la ciudadanía de manera más comprensiva.

Como resultado de la reciente transición al gobierno democrático, América Latina disfruta actualmente de un nivel sin precedentes de derechos políticos ejercidos mediante elecciones razonablemente libres y justas. Las excepciones principales siguen siendo Cuba y, en grado más ambicioso, México. ${ }^{26}$ De manera algo paradójica, dado que las extensas violaciones a los derechos humanos por parte de los regímenes autoritarios fueron una de las causas principales de muchas de las recientes transiciones, los derechos civiles de ciudadanía son todavía en muchos países sumamente precarios para la mayoría (O'Donnell, en prensa y 1993; Holston, 1998; Oxhorn, 1998a; y NACla, 1996). Holston (1998), por ejemplo, estima que más de dos terceras partes de las nuevas democracias en los países en vías de desarrollo son caracterizadas como 'inciviles', debido a las generalizadas violaciones a los derechos civiles. O’Donnell (de próxima publicación) sugiere que este es un problema significativo en todos los países latinoamericanos, con excepción de Uruguay y Costa Rica (una de las democracias más viejas de la región).

En América Latina, los derechos civiles han sido históricamente los más precarios. Esto ha sido resultado directo de la politización del Estado y del consecuente debilitamiento de las instituciones estatales básicas (Karl, 1997; Chalmers, 1977). Los límites de la inclusión controlada también han dado como resul-

${ }^{25}$ De las transiciones recientes a la democracia en América Latina, la única revocación prolongada del gobierno democrático fue el autogolpe del presidente peruano Alberto Fujimori en 1992, en donde el poder constitucional fue suspendido durante aproximadamente un año. (Véanse Cameron, 1998 y Mauceri, 1995.)

${ }^{26}$ Aún en el México autoritario, los ciudadanos han disfrutado de derechos políticos plenos durante muchos años, y durante décadas se han llevado a cabo elecciones regulares. El problema de la democracia aquí tiene más que ver con la efectividad de los derechos políticos y la falta de competencia libre, (minada por el fraude extensivo, la corrupción y algunas veces por la represión) que con la ausencia de éstos. Las reformas electorales recientes y los reveses electorales del gobernante Partido Revolucionario Institucional (PRI) sugieren que esto podría estar cambiando. (Véase Prud 'homme, 1998.) 
tado una represión estatal en diversas formas, cuando las presiones sociales amenazan con rebasar esos límites. En el contexto actual, diversos factores se han combinado para agravar el problema. La falta de derechos civiles yuxtapuesta con los nuevos derechos políticos amenaza con socavar la legitimidad democrática, cuando no la relevancia del gobierno democrático, para la vida diaria de la gente (Garretón, 1998).

El abuso del sistema legal por parte de las élites, la corrupción, y la percepción generalizada de que las autoridades gozan de una cierta impunidad sin importar lo que hagan, también han minado la confianza en las instituciones legales (Hendley, 1996; Garretón, 1995 y 1989). Este es uno de los principales legados autoritarios enfrentados por las nuevas democracias, y en muchos casos tales prácticas no terminan con la transición a la democracia. A esto debe agregarse el problema del personal y las leyes autoritarias que se mantuvieron después del periodo de autoritarismo, y que son difíciles de cambiar. La gente se acostumbra a buscar soluciones extra legales para sus aflicciones, y asume que cualquier reforma fracasará en la práctica, aun si es llevada a cabo por un gobierno electo. A menos que se restaure la confianza en el orden legal, las reformas democráticas se verán minadas, puesto que muchos asumirán que estas reformas no serán más efectivas que en el pasado.

En el contexto actual, por otra parte, los derechos civiles en muchas de las nuevas democracias son directamente socavados por una mercantilización de facto del ejercicio de la ley. En el papel, existe igual protección bajo la ley, pero los pobres no pueden acceder a ella de manera efectiva debido a sus limitados recursos económicos. El Estado es incapaz (por corrupción o por su propia falta de recursos) de llenar ese vacío. En vez de ello, los sistemas legales sirven para fortalecer los problemas estructurales de desigualdad y exclusión social. En un círculo vicioso, las soluciones ineficaces de la corrupción y la impunidad oficial minan aún más la confianza en los sistemas legales, e incluso políticos, y hacen más difícil frenar los abusos.

De manera similar, el ejercicio de la ley a menudo persiste como un instrumento de corrupción y represión, más que como instrumento para el cumplimiento de la reforma legal. Además, en los países que están saliendo de una crisis, el ejercicio de la ley es visto a menudo como enteramente distinto de la reforma legal. Como resultado, ambos instrumentos potenciales de reforma se desarrollan a diferentes velocidades, en vez de hacerlo como un 
proceso coherente y capaz de autofortalecerse. En resumen, las reformas legales pueden anunciarse públicamente, pero no hay ejercicio de esas leyes. El efecto de red que esto crea es una continua desconfianza en las instituciones del país, y un persistente problema de seguridad personal en el nivel local. ${ }^{27}$

La situación se exacerba aún más por el incremento sustancial de las tasas de criminalidad a lo largo de toda América Latina (NACLA, 1996). Además de ser con frecuencia las víctimas principales del crimen, los pobres son a menudo blanco de los esfuerzos policiales por controlar el crimen en lo que toca a la "elevada criminalización de los pobres” (Holston, 1998: 16). Por ejemplo, el significativo incremento de la tasa de crímenes después de la transición a la democracia en El Salvador dio como resultado el pasaje de la Ley de la Emergencia contra la Delincuencia y de la Ley para la Defensa Social, del 19 de marzo de 1996. Estas leyes -de las que algunas partes fueron eventualmente declaradas anticonstitucionales- estipulaban que los individuos serían considerados criminales potenciales, sujetos a encarcelamiento y a la pérdida de sus derechos fundamentales simplemente por su apariencia. Los desempleados, los jóvenes, los pobres, o simplemente aquellos que vestían de manera diferente fueron blanco de leyes que ignoraban los problemas igualmente serios (pero en su mayoría de cuello blanco) del crimen organizado y la corrupción oficial (Proceso, 16: 702, 27 de marzo de 1996). Al mismo tiempo, y de manera particular entre los relativamente acomodados, existe una creciente privatización del ejercicio de la ley a medida que la gente recurre al vigilantismo y contrata seguridad privada. En agudo contraste con los procesos por los que, según Marshall, los derechos ciudadanos se desarrollaron en Gran Bretaña, los capitalistas se han podido adaptar -cuando no aprovechar, en realidad- a las limitaciones de los derechos civiles en gran parte de la región. La mercantilización de los preceptos de la ley, la criminalización de la pobreza, y la privatización del ejercicio de la ley son todas al menos soluciones parciales a las crecientes tasas de criminalidad y a los ineficaces sistemas legales, de las que dispone la gente con recursos económicos. Por otro lado, los intereses empresariales gozan ahora de una creciente influencia en las políticas en América Latina (Mahon, 1996; Keohane y

\footnotetext{
${ }^{27}$ El complicado proceso de reforma e impunidad policial es examinado en Frühling, 1998, para el caso de Chile, y por De Mesquita, 1998, para el caso de Brasil. La lección de la experiencia canadiense de institucionalización de la responsabilidad policial es analizada por Lapkin, 1998.
} 
Milner, 1996; Oxhorn y Docatenzeiler, 1998). Tal influencia se da a menudo a través de canales informales no democráticos, y constituye una fuente fundamental de la precariedad de los derechos civiles. Debido a que los intereses empresariales pueden verse beneficiados con dichas irregularidades -cosa que Marshall no anticipó- éstos no necesariamente van a impulsar el cambio. Como Mahon observó: “...aquellos que mueven los mercados pueden no poner objeción al poder estatal formalmente no atribuido siempre y cuando éste les sea informalmente atribuido a ellos".

La creciente influencia de los intereses económicos en América Latina también refleja la adopción de un nuevo conjunto de políticas neoliberales de desarrollo que han tenido un impacto marcadamente negativo en los derechos sociales de ciudadanía. En su base, estas políticas de desarrollo confían en el mercado para determinar la mejor distribución de los recursos y oportunidades para los pobres.

Las nuevas políticas de bienestar social de asistencia orientada (targeted assistance) son las que mejor representan lo que implica para los derechos sociales este cambio de política de desarrollo. Estas políticas están fundamentadas en el supuesto de que la solución a la pobreza debe darse en el nivel micro, a través de la canalización de las mínimas medidas de bienestar directamente hacia aquellos que más las necesitan. El énfasis se coloca en soluciones a corto plazo que permitirán que esta gente se vuelva autoproductiva a través de su participación en el mercado de trabajo. La confianza en el mercado para determinar la mejor distribución de recursos y oportunidades para los pobres es complementada por el Estado en su papel subsidiario de proporcionar ciertos bienes públicos y transferir ingresos directamente a los más pobres de la sociedad. Los subsidios generales y no uniformes, y las sumamente burocráticas políticas de bienestar son reemplazadas por pagos directos a los usuarios o a los proveedores de servicios, con base estrictamente en la necesidad, en áreas como atención a la salud, educación, nutrición, empleo y vivienda.

La eficiencia de los gastos de bienestar social es supuestamente incrementada al limitar la cantidad de 'filtraciones' a los grupos de clase media y alta. En el área de atención a la salud, por ejemplo, el papel del Estado es minimizado hasta convertirlo en el último recurso. Sólo los indigentes y los pobres que no pueden pagar la seguridad privada serán canalizados a un servicio de salud teóricamente más moderno y eficiente. De manera similar, 
en el área de vivienda de bajo costo, el papel del Estado se reduce a proporcionar subsidios directos y criterios de elegibilidad, dejando que el mercado asegure una oferta adecuada de vivienda de bajo costo una vez que la 'demanda' de los grupos de bajos ingresos es garantizada por el Estado.

La relevancia de esta política puede verse en el hecho de que en años recientes la reducción de la pobreza en la región ha sido resultado, casi en su totalidad, del crecimiento económico y de un incremento concomitante de las oportunidades de empleo para los pobres (Helwege, 1995; CEPAL, 1994). Incluso en Chile, donde el gasto social se incrementó $21 \%$ en términos reales entre 1990 y 1992, más de $80 \%$ del ingreso recibido durante este periodo por $40 \%$ de los hogares más pobres provino de los incrementos en el salario percibido (CEPAL, 1994: 8). Esto implica, sin embargo, que el Estado ha frenado su cumplimiento de cualquier papel distributivo. ${ }^{28}$ Los gastos sociales continúan en amplia regresión; su expansión es cíclica y muy probablemente lo seguirá siendo para mantener la confianza de los inversionistas. De manera similar, las reformas fiscales y las políticas de salario mínimo no han sido usadas en grado significativo para redistribuir el ingreso (Helwege, 1995). Las políticas diseñadas para lidiar con las causas estructurales de la pobreza y la desigualdad, particularmente a través de las inversiones de capital humano en educación y atención a la salud, son sacrificadas a favor de las prioridades a corto plazo para mantener el equilibrio económico, bajo el supuesto de que los programas orientados a los más necesitados proporcionarán el tiempo necesario para que la economía genere más empleos.

Estos cambios en la política han afectado severamente el equilibrio social en la región, combinados además con el creciente problema de las tasas de criminalidad en ascenso vertiginoso. La renovación del crecimiento económico en América Latina después de la crisis económica de la década de los años ochenta ha fracasado, en general, en su intento por disminuir los niveles de desigualdad a aquellos experimentados en la década de los años setenta (Altimir, 1994 y 1995). ${ }^{29}$ Esto a pesar de las algunas

${ }^{28} \mathrm{Si}$ bien esto es claramente una elección de políticas, también puede reflejar cambios en la estructura del propio Estado, lo que ha limitado la capacidad institucional de éste para redistribuir los recursos económicos, aun cuando exista voluntad política para hacerlo.

${ }^{29}$ La principal excepción es Colombia, en donde la desigualdad era en realidad más baja que antes de la crisis económica. Pero aquí la amenaza más evidente para la sociedad civil es la penetrante violencia ligada al narcotráfico, las insurgencias izquierdistas 
veces significativas reducciones de la pobreza. Altimir (1994: 26) concluye que:

En suma, los patrones distributivos 'normales' en la fase entrante de crecimiento sostenido, cuando éste se materializa en la mayor parte de los países de América Latina, una vez que éstos se han recuperado de la crisis y sus secuelas, que han completado los ajustes estructurales y desplegado las reformas a las políticas, tienden a ser más desiguales -al menos en las zonas urbanas- que aquellos patrones prevalecientes en la última fase del crecimiento, durante los 70 .

La mirada a largo plazo no es mejor desde esta perspectiva. Enrique Iglesias, presidente del Banco Interamericano de Desarrollo, advirtió que:

En condiciones de crecimiento estable, podría tomar al continente muchos años, -entre 50 y más de un siglo, dependiendo del país- otorgar a todos sus ciudadanos un nivel mínimo de bienestar con las tendencias actuales de distribución (New York Times, 25 de marzo de 1998: A7).

Esta coincidencia única de derechos civiles limitados, derechos sociales en declive y derechos políticos casi universales de ciudadanía refleja una debilidad de la sociedad civil que se desprende tanto de la naturaleza de las transiciones recientes, como de los patrones actuales de desarrollo económico. En particular, la dominación ejercida en estas transiciones por los partidos políticos y por las élites ha obstaculizado el desarrollo de las sociedades civiles latinoamericanas. ${ }^{30}$

Aunque la movilización popular en general jugó un papel importante al precipitar las transiciones democráticas, las élites y los partidos políticos determinaron en última instancia su curso

y las políticas de contrainsurgencia del gobierno. Además, los elevados niveles de corrupción y la debilidad de las principales instituciones del Estado, como la judicial, implican que los derechos civiles son tan precarios ahí como lo son en el resto de la región, si no es que más. Uruguay y Costa Rica se estaban aproximando a sus niveles anteriores de desigualdad. Estos países disfrutaban también de las sociedades civiles más fuertes de América Latina, lo que puede ayudar a explicar por qué las tendencias regresivas del modelo neoliberal de desarrollo fueron hasta cierto punto mitigadas. También es importante resaltar que Uruguay ha logrado sólo un mínimo progreso en la implantación de las reformas estructurales requeridas por el modelo, en gran medida debido al rechazo de los votantes uruguayos a abandonar las instituciones principales de su Estado benefactor.

${ }^{30}$ Es importante enfatizar que con este argumento no estoy sugiriendo que necesariamente se careciera de alternativa. Y quizá más importante, en contraste con algunos autores (por ejemplo Petras y Vieux, 1994), no pretendo sugerir que el otorgar derechos políticos no haya sido un cambio positivo de enorme relevancia para la gran mayoría de los latinoamericanos. En vez de ello, quiero analizar algunas de las limitaciones de estas transiciones para que éstas puedan ser corregidas en el futuro. 
final (O’Donnel y Schmitter, 1986; Oxhorn, 1995a). ${ }^{31}$ La expresión más clara de esto se encuentra en los pactos políticos a través de los cuales se establecieron en muchos casos no sólo las reglas del juego para el futuro régimen democrático, sino que se marcaron límites en los temas sustantivos que los gobiernos electos podían tratar (Karl, 1986). Entre esos límites había importantes concesiones al régimen autoritario saliente en términos de futuros procesos por violación a los derechos humanos, así como el mantenimiento de diversos enclaves autoritarios al interior de las instituciones de la nueva democracia (Garretón, 1989).

El proceso por medio del cual las élites y los partidos políticos llegaron a dominar el proceso político durante las últimas fases de la transición necesariamente ocasionó una desmovilización de los actores masivos, y su subordinación al interés de asegurar una transición democrática exitosa. Esta desmovilización, sin importar cuan necesaria haya sido para evitar cualquier posible regresión al autoritarismo, no se dio sin tensión. En esencia, acortó el proceso de construcción de la sociedad civil, que había dado inicio como preludio a la transición. Estas tensiones sólo fueron exacerbadas por la continua dominación de las élites, particularmente de las élites partidistas, después de la transición, y por la percepción generalizada de una creciente distancia entre los líderes del partido y el resto de la población. El 'espacio' disponible para la participación popular a menudo parecía circunscrito al proceso electoral en sí mismo. Además, con frecuencia existía un sentimiento de frustración dadas las limitaciones de los cambios reales logrados en el despertar democrático. El resultado ha sido un declive general en la actividad organizativa en el interior de la sociedad civil, aun en aquellos países donde esa actividad había alcanzado niveles relativamente altos durante el régimen autoritario.

Otros diversos factores han afectado el grado en que la sociedad civil ha tendido a retraerse bajo el gobierno democrático. En muchos países, la actividad organizativa autónoma entre grandes segmentos de la población fue un fenómeno relativamente nuevo. A menudo fue resultado de las exigencias de supervivencia durante el brutal gobierno autoritario (Oxhorn, 1995a y 1995b). Una vez que la transición se había completado exitosamente, las experiencias organizativas aprendidas durante las dictaduras tenían que ser trasladadas de manera efectiva a un entor-

${ }^{31}$ Algunos de estos temas se discuten con mayor amplitud en Oxhorn, 1996. 
no democrático (con todas sus deficiencias), y esto no fue tarea fácil. Para los jóvenes en particular, los miembros de muchas de las organizaciones que surgieron durante el periodo de gobierno autoritario no tenían experiencia con la política democrática. Sus estilos organizativos y el tipo de demandas que se estaban articulando debían adaptarse a un escenario muy diferente.

Para complicar el problema, estaba el hecho de que ya no había ningún 'enemigo' no ambiguo contra el cual movilizarse. La dictadura tenía que ser reemplazada ahora por un gobierno civil electo. Sin un enemigo claro para catalizar la movilización popular, ésta se volvió a menudo problemática. Por otro lado, la mayoría de las personas activamente involucradas en las diversas organizaciones que habían surgido durante el periodo de dictadura aún veía a la democracia como un fin en sí mismo, a pesar de sus deficiencias. Irónicamente, este compromiso con la democracia política puede, de hecho, haber complicado el problema de la actividad organizativa autónoma de los sectores populares. Los líderes potenciales de esa movilización a menudo seguían estando inseguros respecto a cómo expresar su creciente frustración, y muchos de ellos nunca habían participado en la política democrática y no sabían cómo beneficiarse de las oportunidades de participación que ésta les pudiera ofrecer. Al mismo tiempo, temían que la movilización pudiera crear presiones desestabilizadoras que amenazaran la viabilidad del nuevo régimen democrático. Bajo el gobierno autoritario, esas personas o bien no pensaban acerca de los efectos potencialmente desestabilizadores de sus actividades, o tenían esto como objetivo explícito. Ahora el temor (a menudo coreado, cuando no fomentado, por las élites políticas) era que cualquier movilización autónoma fuera contraproducente.

Esta experiencia general contrasta fuertemente con la de la movilización de la clase obrera en Gran Bretaña discutida por Marshall. Ahí, la movilización se buscó de manera deliberada para cambiar un régimen existente (y, para los estándares de la época, ampliamente democrático) más que para derrocar un régimen autoritario a menudo violento. Puesto que el cambio de régimen era la demanda dominante, si no es que la única, de los actores involucrados en las transiciones recientes, hubo una tendencia a ver a los derechos políticos casi como una panacea para resolver una diversidad de males sociales, más que como un pun- 
to de partida indispensable. ${ }^{32} \mathrm{La}$ ruptura con el pasado no sólo fue menos dramática en el caso británico, sino que fue delibera$d a$. Mientras que las transiciones latinoamericanas acortaron el proceso de construcción de la sociedad civil, en Gran Bretaña el proceso fue más continuo y acumulativo -de aquí la aparente teleología del análisis de Marshall.

El contraste es aún más claro cuando se da un vistazo a las organizaciones obreras en ambos casos. El movimiento laboral británico se vio significativamente fortalecido como resultado de sus luchas para conquistar derechos civiles importantes, y tuvo continuidad al ayudar a crear el Partido Laborista Británico y asegurar su integración política. En la mayoría de los países latinoamericanos, los trabajadores organizados jugaron un papel importante en la movilización que ayudó a realizar las transiciones a la democracia (Valenzuela, 1989; Drake, 1996), pese a que su situación sigue siendo sumamente débil en prácticamente todos los países de la región. ${ }^{33}$ Los movimientos laborales a lo largo de América Latina han visto considerablemente mermada su membresía como resultado de la severa represión y de la depresión económica ocasionada por la profunda crisis de la década de los años ochenta. Además, los sindicatos fueron muy golpeados por el retroceso en los derechos sociales que habían conquistado en periodos anteriores, como resultado de la adopción de las políticas económicas neoliberales (Oxhorn, 1998a).

El resultado general ha sido una extrema fragmentación de la sociedad civil en la mayoría de los países de la región. El incremento de la desigualdad social, la pronunciada desmovilización de las masas, y una actividad organizativa comparada a la del periodo anterior a las transiciones recientes, y en particular el debilitamiento de las organizaciones laborales son factores que han frenado los procesos que de otra manera podrían haber surgido de la sociedad civil para lograr la expansión efectiva de los derechos ciudadanos. En un proceso que es casi el inverso del

\footnotetext{
${ }^{32}$ Dada la severidad de las violaciones a los derechos humanos, semejante visión es ciertamente comprensible puesto que los gobiernos civiles electos generalmente han tenido mejor historia con respecto a los derechos humanos que su predecesores autoritarios. Aún así es interesante resaltar que la orientación general de las transiciones en sus últimas etapas se enfocó más o menos de manera exclusiva a los derechos políticos, aunque mucha de la organización o la resistencia real bajo el régimen autoritario se centraba primero en el establecimiento de derechos humanos/civiles fundamentales y en la protección de los derechos sociales mínimos que eran en general muy atacados.

${ }^{33}$ Brasil es una excepción parcial, en donde la rápida industrialización de las décadas de los años sesenta y setenta, así como la considerable influencia política del Partido de los Trabajadores (PT) han contribuido a un crecimiento significativo de las fuerza de los sindicatos durante la década de 1980. (Véase Keck, 1992.)
} 
círculo virtuoso del análisis de Marshall acerca de los derechos ciudadanos, la democracia en América Latina ha seguido restringiendo el potencial de la sociedad civil a pesar de la universalización, en los últimos años, de los derechos políticos.

\section{Conclusiones}

Regresando a la reflexión fundamental de Marshall acerca de que la desigualdad socioeconómica pudo legitimarse en las democracias occidentales sólo mediante la extensión y expansión gradual de los derechos universales de ciudadanía, queda claro que la democracia latinoamericana enfrenta graves desafíos. No únicamente se ha incrementado la desigualdad en términos de ingreso en dinero, sino que la brecha entre el ingreso real y el ingreso en dinero se ha hecho aún más grande en una región considerada durante mucho tiempo entre las más desiguales del mundo. Lejos de legitimar la desigualdad social, los derechos políticos de ciudadanía, en su incapacidad tan sólo para revertir esta brecha, se arriesgan a minar su legitimidad, abriendo camino a las alternativas antidemocráticas. De acuerdo con Enrique Iglesias, presidente del Banco Interamericano de Desarrollo, las encuestas de opinión pública muestran que sólo $27 \%$ de los latinoamericanos confía en las actuales instituciones democráticas (New York Times, 25 de marzo, 1998: A7). Puesto que los gobiernos democráticos han demostrado ser incapaces y/o poco dispuestos a hacerse cargo de las principales preocupaciones de sus ciudadanos, la democracia en sí misma está en riesgo de volverse irrelevante a medida que la gente continúa buscando formas para proveerse por sí misma de una vida mejor (Garretón, 1998).

Al tratar de analizar el papel de la sociedad civil en la construcción social de los derechos de ciudadanía queda claro que la debilidad de la sociedad civil en América Latina es tanto una consecuencia, como una causa de los caminos que ha seguido la región en la evolución de los derechos universales de ciudadanía. La mayor dispersión de los recursos de poder hacia el interior de la sociedad civil permitió una serie de luchas en las que hubo un incremento acumulativo tanto en el contenido de los derechos ciudadanos, como en la fuerza de la sociedad civil. A principios de este siglo en América Latina (y en otros lugares), los derechos sociales de ciudadanía fueron a menudo obtenidos en ausencia de derechos políticos y civiles, como un mecanismo de control social y cooptación que deliberadamente obstruía la clase de pro- 
cesos acumulativos implícitos en la descripción de Marshall acerca de los derechos de ciudadanía en Gran Bretaña. Más recientemente, tanto los derechos sociales como los civiles han sido restringidos, a pesar de la existencia de derechos políticos sustanciales. El efecto ha frustrado el desarrollo de la sociedad civil, y pone en duda el futuro de la democracia en la región.

Si bien el desarrollar soluciones específicas rebasa los alcances de este trabajo, delinearé brevemente tres posibles puntos de partida.

Uno de ellos es la inversión de más recursos para el ejercicio de la ley y los procesos judiciales, incluyendo mayores esfuerzos y una reforma legal. Como Marshall acertadamente argumenta, los derechos civiles son esenciales para los derechos políticos efectivos (por no mencionar los derechos sociales) de ciudadanía. Irónicamente, la defensa de Marshall respecto a las oficinas de defensa pública para asegurar el acceso al sistema legal a aquellos que están en desventaja en la sociedad, como quizá el último escalón en el desarrollo de los derechos sociales, resulta particularmente relevante hoy en día para América Latina, en donde los derechos sociales tienen un largo camino que recorrer antes de poder siquiera comenzar a rivalizar con aquellos de la Gran Bretaña de la posguerra.

En segundo lugar, existe la necesidad de utilizar el inmenso aparato nacional e internacional de los derechos humanos que surgió durante el periodo de los gobiernos autoritarios para asegurar derechos civiles efectivos y construir sociedades civiles más fuertes en los gobiernos democráticos. Los derechos humanos pueden incluso entenderse mejor como derechos ciudadanos en un contexto democrático. Los esfuerzos anteriores para reducir la represión política estatal podrían redirigirse para ayudar a crear derechos ciudadanos al frenar los abusos policiales y judiciales. La experiencia obtenida al organizar una miríada de grupos a favor de los derechos humanos durante las dictaduras podría aplicarse de manera similar para ayudar a los diversos grupos en el interior de la sociedad civil a organizarse de manera que puedan comenzar a definir y defender sus intereses a través de las instituciones democráticas.

Finalmente, el Estado tiene un papel importante que jugar. En primer lugar, es necesario reformar las instituciones estatales (algunas veces de manera sustancial) para garantizar derechos civiles y sociales de ciudadanía que sean eficaces. Más allá de eso, el Estado puede jugar un papel al proporcionar ayuda técnica y 
material a los nuevos grupos dentro de la sociedad civil. La tentación de emplear esos recursos con fines partidistas es evidentemente un peligro real, pero las democracias occidentales -incluyendo la británica analizada por Marshall- han desarrollado mecanismos para asegurar al menos cierto grado de imparcialidad. Esta alternativa 'neocorporativista', por otro lado, tendría que proporcionar un nivel mucho más elevado de autonomía con respecto a las organizaciones societales de lo que ha sido el caso en el pasado de América Latina. ${ }^{34}$

Los desafíos son evidentemente enormes, especialmente dada la fragilidad de muchos de los nuevos regímenes democráticos. Una vez especificados los riesgos, sin embargo, estos desafíos no pueden ser ignorados.

\section{Bibliografía}

Almond, G. (1973), “Approaches to development causation”, en G. Almond et al., Crisis, choice and change: Historical studies of political development, Boston, Little Brown and Co., pp. 1-39.

Altimir, O. (1995), "Inequality, employment and poverty in Latin America: An overview", documento presentado en la conferencia Poverty in Latin America: Issues and New Responses, Kellogg Institute for International Studies, University of Notre Dame, septiembre 30 - octubre 1.

_ (1994), "Income distribution and poverty through the crisis and adjustment", CEPAL Review, 52, abril, pp. 7-31.

Álvarez, S. (1990), Engendering democracy in Brazil: Women's movements in transition politics, Princeton University Press, Princeton.

Anderson, B. (1991), Imagined communities, Verso, London.

Beiner, R. (ed.) (1995), Theorizing citizenship, State University of New York Press, Albany.

${ }^{34}$ Se hace aquí la distinción entre el corporativismo 'societal' característico de la Europa de la posguerra y el corporativismo 'estatal' que a menudo caracterizó los tempranos procesos de inclusión controlada en América Latina (Schmitter, 1974, y Oxhorn, 1998a). (Véase Schmitter, 1998 para una discusión de la alternativa neocorporativista en el contexto de la Unión Europea.) 
Bendix, R. (1964), Nation-building and citizenship: Studies of our changing social order, John Wiley \& Sons, New York.

Black, A. (1984), Guilds and civil society in European political thought from the Twelfth Century to the present, Methuen \& Co., London.

Brenner, R. (1976), "Agrarian structures and economic development in pre-industrial Europe", Past and present, febrero, pp. 30-75.

Calhoun, C. (1991), "The problem of identity in collective action", in J. Huber (ed.), Macro-micro linkages in Sociology, Sage Publications, Newbury Park, pp. 51-75.

Chalmers, D. (1977), "The politicized state in Latin America", in J. Malloy (ed.), Authoritarianism and corporatism in Latin America, University of Pittsburgh Press, Pittsburgh, pp. 23-45.

Collier, R. B. y David Collier (1991), Shaping the political arena, Princeton University Press, Princeton.

De Mesquita, P. (1998), "Police reform in Latin American emerging democracies: The experience of Brazil”, documento presentado en la conferencia Democracy and the rule of institutionalizing citizenship rights in new democracies, McGill University, Montreal, marzo 19-20.

Deutsch, K. (1961), "Social mobilization and political development", American political science Review, 55, septiembre, pp. 493-514.

Drake, P. (1996), Labor movements and dictatorships: The Southern Cone in comparative perspective, The Johns Hopkins University Press, Baltimore.

Economic Commission for Latin America and the Caribbean (ECLAC) (1994), Social panorama of Latin America, ECLAC, Santiago. 
Einhorn, B. (1991), "Where have all the women gone? Women and the women's movement in Eastern Central Europe", Feminist Review, 39, invierno, pp. 16-36.

_ (1989), “Socialist emancipation: The women's movement in the German Democratic Republic", en S. Kruks, R. Rapp y M. B. Young (eds.), Promissory Notes, Monthly Review Press, New York, pp. 282-305.

Evers, T. (1985), "Identity: the hidden side of new social movements in Latin America", en D. Slater (ed.), New social movements and the state in Latin America, CEDLA, Amsterdam, pp. 43-71.

Foweraker, J. y T. Landman (1997), Citizenship rights and social movements: A comparative and statistical analysis, Oxford University Press, Oxford.

Frühling, H. (1998), "Implementing enforceable laws: The difficult transition of the Carabineros in Chile", documento presentado en la conferencia Democracy and the Rule of Law: Institutionalizing citizenship rights in new democracies, McGill University, Montreal, marzo 19-20.

Garretón, M. A. (1995), "Social and economic transformations in Latin America: The emergence of a new political matrix?", en P. Oxhorn and P. Starr (eds.), Markets and democracy in Latin America: Conflict or convergence?, Lynne Rienner, Boulder, Colo.

— (1995), "Redemocratization in Chile”, Journal of Democracy, 6 .

_ (1989), The Chilean political process, Unwin Hyman, Boston.

Helwege, A. (1995), "Poverty in Latin America: Back to the abyss?", Journal of Interamerican Studies and World Affairs, 37, otoño, pp. 99-123.

Hendley, K. (1996), "Legitimizing judicial institutions: Russian economic courts in transition", documento presentado en 
la conferencia Democracy and the Rule of Law: Institutionalizing Citizenship Rights in New Democracies, McGill University, Montreal, marzo, 19-20.

Hobson, B. y M. Lindholm (1997), “Collective identities, women's power resources and the making of welfare states", Theory and Society, 26, agosto, pp. 475-508.

Holston, J. (1998), “Citizenship in uncivil democracies”, documento presentado en la conferencia Democracy and the Rule of Law: Institutionalizing Citizenship Rights in New Democracies, McGill University, Montreal, marzo19-20.

Huntington, S. (1971), "The change to change: Modernization, development and politics", Comparative Politics, III, abril, pp. 283-322.

Jacquette, J. (ed.) (1989), The women's movement in Latin America: feminism and the transition to democracy, Unwin Hyman, Boston.

Jelin, E. (ed.) (1990), Women and social change in Latin America, Zed Books Ltd. London.

_ $\quad$ y E. Herschberg (1996), Constructing democracy: human rights and society in Latin America, Westview Press, Boulder.

Karl, T. (1997), The paradox of plenty: Oil booms and petro states, University of California, Berkeley.

_ (1992), "El Salvador's negotiated revolution”, Foreign Affairs, 71, primavera, pp. 147-164.

_ (1986), "Petroleum and political pacts: The transition to democracy in Venezuela", en G. O'Donnell, P. Schmitter and L. Whitehead (eds.), Transitions from authoritarian rule: Southern Europe, Johns Hopkins University Press, Baltimore, pp. 196-219.

Keck, M. (1992), The workers' party and democratization in Brazil, Yale University Press, New Haven. 
Keohane, R. y H. Milner (eds.) (1996), Internationalization and Domestic Politics, Cambridge University Press, Cambridge.

Lapkin, G. (1998), "A globalized approach to public accountability: How citizens can watch the watchmen", documento presentado en la conferencia Democracy and the Rule of Law: Institutionalizing Citizenship Rights in New Democracies, McGill University, Montreal, marzo 19-20.

Lipset, S. M. (1959), "Some social requisites of democracy: Economic development and political legitimacy", American Political Science Review, 53, marzo, pp. 69-105.

Lynch, J. (1973), The Spanish American revolutions, 1808-1826, Norton, New York.

Mahon, J. (1996), Mobile capital and Latin American Development, The Pennsylvania State University Press, University Park.

Mann, M. (1996), "Ruling class strategies and citizenship", en M. Bulmer y A. Rees (eds.), Citizenship Today: The contemporary relevance of T. H. Marshall, UCL Press Ltd., London, pp. 125-144.

Marshall, T. H. (1950), Citizenship and social class and other essays, Cambridge University Press, Cambridge.

Mauceri, P. (1995), "State reform, coalitions and the neoliberal autogolpe in Peru", Latin American Research Review 30, núm. 1, pp. 7-37.

Melucci, A. (1985), "The symbolic challenge of contemporary movements", Social Research, 52, invierno, pp. 789-816.

Middlebrook, K. (1995), The paradox of revolution: Labor, the State and Authoritarianism in Mexico, Johns Hopkins University Press, Baltimore.

Moore, B. (1966), The social origins of dictatorship and democracy, Beacon Press, Boston. 
Mouffe, C. (ed.) (1992), Dimensions of radical democracy: Pluralism, Citizenship, Community, Verso, London.

NACLA (1996), "Report on crime and impunity", Report on the Americas, 30, septiembre/octubre, pp. 17-43.

O’Donnell, G. (forthcoming), "Polyarchies and the (Un)Rule of law in Latin America”, en J. Méndez, G. O’Donnell and P. Pinheiro (eds.), The Rule of Law and the Underprivileged in Latin America, University of Notre Dame Press, Notre Dame.

_ (1994), “Delegative democracy”, Journal of Democracy, 5, enero, pp. 56-69.

_ (1993), "On the State, democratization and some conceptual problems: A Latin American view with glances at some postcommunist countries", World Development, 21, núm. 8, pp. 1355-1369.

_ (1979), "Tensions in the bureaucratic authoritarian state and the question of democracy", en D. Collier (ed.), The New Authoritarianism in Latin America, University of Princeton Press, Princeton.

_ y P. Schmitter (1986), Transitions from Authoritarian Rule: Tentative conclusions about uncertain democracies, Johns Hopkins University Press, Baltimore.

Offe, C. (1987), "Challenging the boundaries of institutional politics: Social movements since the 1960s", en C. Maier (ed.), Changing boundaries of the political, Cambridge University Press, Cambridge, pp. 63-106.

Oxhorn, P. (1998a), "Is the century of corporatism over? Neoliberalism and the rise of neopluralism", en P. Oxhorn and G. Ducatenzeiler (eds.), What kind of democracy? What kind of market? Latin American in the age of neoliberalism, The Pennsylvania State University Press, University Park. 
— Oxhorn, P. (1998b), "The social foundations of Latin America's recurrent populism: Problems of class formation and collective action", Journal of Historical Sociology 11, junio, pp. 212-246.

_ (1996), "Surviving the return to 'normalcy': Social movements, democratic consolidation and economic restructuring”, International Review of Sociology, vol. 6, núm. 1, pp. 117-134.

- (1995a), Organizing civil society: The popular sectors and the struggle for democracy in Chile, The Pennsylvania State University Press, University Park.

1995b), "From controlled inclusion to reactionary exclusion: The struggle for civil society in Latin America", en J. Hall (ed.), Civil society: Theory, history and comparison, Polity Press, Cambridge, pp. 250-277.

- y G. Ducatenzeiler (eds.) (1998), What kind of democracy? What kind of market? Latin America in the age of neoliberalism, The Pennsylvania State University Press, University Park.

Petras, J. y S. Vieux (1994), “The transition to authoritarian electoral rule", Latin American Perspectives, 21, otoño, pp. 520 .

Portes, A. (1974), "Modernity and development: A critique", Studies in Comparative International Development, 9, primavera, pp.247-279.

Prud'homme, J. (1998), "Interest representation and the party system in Mexico", en P. Oxhorn y G. Ducatenzeiler (eds.), What kind of democracy? What kind of market? Latin America in the age o neoliberalism, The Pennsylvania State University Press, University Park.

Przeworski, A., M. Álvarez, J. A. Cheibub y F. Limongi (1996), "What makes democracies endure?", Journal of Democracy, 7, enero, pp.38-55. 
Przeworski, A. et al. (1995), Sustainable Democracy, Cambridge University Press, Cambridge.

- (1986), "Some problems in the study of the transition to democracy", en G. O’Donnell, P. C. Schmitter y L. Whitehead (eds.), Transitions form authoritarian rule: Comparative perspectives, The Johns Hopkins University Press, Baltimore, pp. 47-63.

_ (1985), Capitalism and social democracy, Cambridge University Press, Cambridge.

Rees, A. (1996), “T. H. Marshall and the progress of citizenship", in M. Bulmer y A. Rees (eds.), Citizenship today: The contemporary relevance o T. H. Marshall, UCL Press Ltd., London, pp. 1-23.

Roberts, B. (1996), “The social context of citizenship in Latin America", Journal of Urban and Regional Research, 20, marzo, pp. 8-65.

Rubin, J. (1997), Decentering the Regime: Ethnicity, radicalism and democracy in Juchitán, México, Duke University Press, Durham, N. C.

Rueschemeyer, D., E. Stephens y J. Stephens (1992), Capitalist development and democracy, University of Chicago Press, Chicago.

Schmitter, P. y T. Karl (1991), "What democracy is... And is not", Journal of Democracy, 3, verano, pp. 75-88.

Schmitter, P. (1986), "An introduction to Southern European transitions from authoritarian rule", en G. O'Donnell., P. Schmitter and L. Whitehead (eds.), Transitions form authoritarian rule: Southern Europe, The Johns Hopkins University Press, Baltimore, pp. 3-10.

Schmitter, P. C. (1974), "Still the century of corporatism?", Review of Politics, 36, enero, pp. 85-131. 
Schmitter, P. (1998), "Citizenship without nationality or can there be such a thing as a European citizenship?", documento presentado en la conferencia Democracy and the Rule of Law: Institutionalizing Citizenship Rights in New Democracies, McGill University, Montreal, marzo 19-20.

Smith, W., C. Acuña y E. Gamarra (eds.) (1994), Latin American political economy in the age of neoliberal reform: Theoretical and comparative perspectives for the 1990s, Transaction Publishers, University of Miami North-South Center-New Brunswick, Miami.

Steinberg, M. (1996), “The great end of all government...': Working people's construction of citizenship claims in early Nineteenth-Century England and the matter of class", en C. Tilly (ed.), Citizenship, identity and social history, International Review of Social History Supplement 3, Press Syndicate of the University of Cambridge, Cambridge, pp. 19-50.

Subramanian, N. (1995), Bringing society back in: Ethnicity, populism and pluralism in South India, , McGill University, Department of Political Science, Montreal, mimeo.

Taylor, C. (1990), "Invoking civil society", Working Papers and Proceedings of the Center for Psychosocial Studies, núm. 31, Center for Psychosocial Studies, Chicago.

Tilly, C. (ed.) (1996a), "Citizenship, identity and social history”, International Review of Social History, Supplement 3, Press Syndicate of the University of Cambridge, Cambridge.

_ (1996b), "Citizenship, identity and social history", en C. Tilly (ed.), Citizenship, identity and social history, International Review of Social History Supplement 3, Press Syndicate of the University of Cambridge, Cambridge, pp. $1-17$.

Turner, B. (1993), Citizenship and social theory, Sage Publications, London. 
_ (1992), "Outline of a theory of citizenship", en C. Mouffe (ed.), Dimensions of radical democracy: Pluralism, citizenship, community, Verso, London, pp. 33-62.

Usher, Dan (1981), The economic prerequisite to democracy, Columbia University Press, New York.

Valenzuela, J. S. (1989), "Labor movements in transitions to democracy: A framework for analysis", Comparative Politics, 21, julio, pp. 445-472.

Vaughan, M. K. (1997), Cultural politics in revolution: Teachers, peasant, and schools in Mexico, 1930-1940, University of Arizona Press, Tucson.

Waylen, G. (1994), "Women and democratization: Conceptualizing gender relations in transition politics", World Politics, 46, abril, pp. 327-354.

Wickham-Crawley, T. (1989), "Winners, losers, and also-rans: Toward a comparative sociology of Latin American guerrilla movements", en S. Eckstein (ed.), Power and popular protest: Latin American social movements, University of California Press, Berkeley, pp. 132-181.

Zamosc, L. (1989), "Peasant struggles of the 1970s in Colombia”, en S. Eckstein (ed.), Power and popular protest: Latin American social movements, University of California Press, Berkeley, pp. 102-131.

Enviado: 19 de julio de 2000 Aceptado: 21 de febrero de 2001 
